\title{
dspace.vutbr.cz
}

\section{Determination of optimum high-side pressure of R744 automotive heat pump using Fibonacci search method}

\author{
GLOS, J.; ŠOLC, F.
}

Proceedings of the 2017 IEEE International Symposium on Industrial Electronics

pp. $448-453$

Electronic ISBN: 978-1-5090-1412-5

Electronic ISSN: 2163-5145

DOl: http://dx.doi.org/10.1109/ISIE.2017.8001288

Accepted manuscript

(C)2017 IEEE. Personal use of this material is permitted. Permission from IEEE must be obtained for all other uses, in any current or future media, including reprinting/republishing this material for advertising or promotional purposes, creating new collective works, for resale or redistribution to servers or lists, or reuse of any copyrighted component of this work in other works. Jan Glos, Frantisek Solc, "Determination of optimum high-side pressure of R744 automotive heat pump using Fibonacci search method", Proceedings of the 2017 IEEE International Symposium on Industrial Electronics, pp. 448-453, 2017. DOI: 10.1109/ISIE.2017.8001288. Final version is available at http://ieeexplore.ieee.org/document/8001288/ 


\section{Determination of optimum high-side pressure of R744 automotive heat pump using Fibonacci search method}

\author{
Jan Glos \\ CEITEC - Central European Institute of Technology \\ Brno University of Technology \\ Brno, Czech Republic \\ Email: jan.glos@ceitec.vutbr.cz
}

\author{
Frantisek Solc \\ CEITEC - Central European Institute of Technology \\ Brno University of Technology \\ Brno, Czech Republic \\ Email: solc@feec.vutbr.cz
}

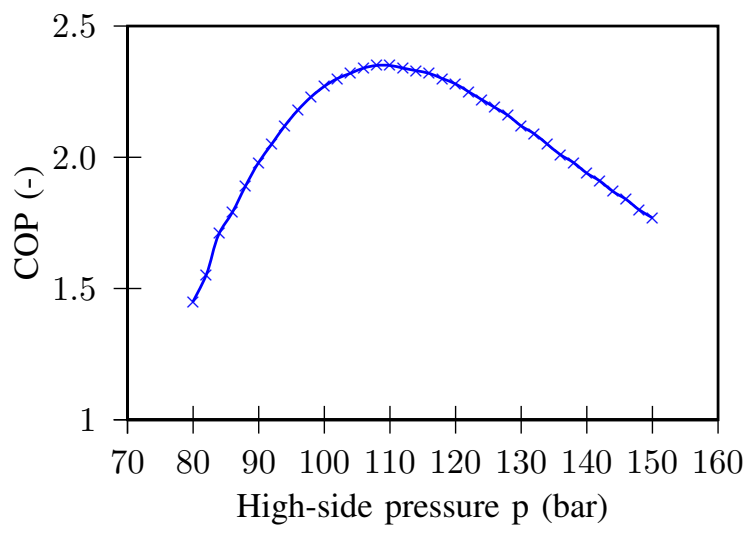

Fig. 1. An example of COP dependence on high-side pressure under fixed conditions.

Abstract-This paper deals with maximizing coefficient of performance (COP) of R744 automotive heat pump. A highside pressure variation is possible during transcritical operation employing low pressure receiver and electronic expansion valve (EXV). The optimal high-side pressure is then determined using Fibonacci search method. This approach is one of possible methods of online high-side pressure control and it has significant advantages over the offline methods. Employing this innovative method of R744 heat pump optimization a disadvantage of low COP during transcritical operation can be eliminated. Thus further usage of $\mathrm{R744}$ refrigerant in automotive applications will be possible without any negative impact on energy consumption. As a result, this work can help with development of more environmental friendly vehicles.

\section{INTRODUCTION}

$\mathrm{CO}_{2}$ as a refrigerant $\mathrm{R} 744$ was used in marine and other systems in early 20th century [1]. After chlorofluorocarbon (CFC) invention R744 was gradually displaced by CFC-based refrigerants [2], which have high ozone depletion potential (ODP). That is why the Montreal Protocol was signed in 1987 and thus began the elimination of CFC refrigerants, which was totally completed in 2010 [3]. Hydrofluorocarbon (HFC) refrigerants are today widely used (for example R134a, R404a and others), but they have quite high global warming potential (GWP). Therefore European Directive 2006/40/EC was approved, which restricts usage of refrigerants with GWP greater than 150 in automotive applications. There are two promising refrigerants meeting this condition, R744 $\left(\mathrm{CO}_{2}\right)$ and R1234yf. Both of them have their advantages and disadvantages. On the one hand, R1234yf can be used in heat pumps intended for R134a [4], so there is no need to design new components. On the other hand, R1234yf is classified as flammable [4], what can affect its usage. Regarding the thermodynamic properties, $\mathrm{R} 1234 \mathrm{yf}$ is very similar to widely used R134a.

R744 $\left(\mathrm{CO}_{2}\right)$ is not flammable, but due to its very low critical point at temperature of $304.1 \mathrm{~K}\left(31.1^{\circ} \mathrm{C}\right)$ and pressure of $7.38 \mathrm{MPa}$ [2] the heat pump with this refrigerant will under some conditions operate in supercritical region. Moreover, the working pressures are significantly higher and R744 has also substantially higher volumetric heat capacity, both compared with other refrigerants. Therefore all of the components must be adapted to these properties. However, all components might be a little smaller and lightweight (despite the need to maintain higher pressures) [5].

R744 heat pump operating in subcritical conditions works similarly as if conventional refrigerants like R134a or R410a were used. But after a transition to a transcritical region the heat rejection temperature is not anymore dependent on heat rejection pressure [6]. It is well known that coefficient of performance (COP) of a transcritical cycle strongly depends on high-side pressure [1], [7]. Hence it is necessary to employ some kind of high-side pressure control to achieve efficient heat pump operation. Many simulations show that the problem can be solved by help of an unimodal optimization. In Fig. 1 a typical dependence of COP on high-side pressure is shown, the data were obtained by simulating heat pump under fixed conditions and with variable high-side pressure setpoint.

If we ignore various options of cycle configuration as this paper does not deal with it, there are two basic ways to control the high-side pressure. The first one is based on tabular data measured during various conditions or on some equation allowing calculation of optimal high-side pressure according to the measured temperatures and possibly pres- 
sures [6], [8]-[11]. The advantages of this kind of methods are simple determination of optimal high-side pressure, low computational requirements and usually overall ease of use. The main drawbacks contain the need of measurements under various conditions or the need to select (or assemble) the appropriate equation and the impossibility to response to different conditions changes and disturbances (dirty gas cooler, partially frozen evaporator etc.).

Thus the second approach to high-side pressure control was proposed, sometimes referred as an "online". These methods are not based on static equation nor on the tabular data, but perform a real-time optimization of high-side pressure to obtain the maximum COP value. According to [12] the online methods can prevent large COP loss in comparison with offline ones. This approach was examined several times and promising results were obtained [13]-[15].

In this paper we propose an online algorithm of optimal high-side pressure optimization based on Fibonacci optimum seeking method. It is said to be the best optimum search method for the first dimension functions [16] and that is the reason for our choice.

\section{FIBONACCI SEARCH METHOD}

Fibonacci optimum seeking (FOS) method is a convenient method for finding minimum or maximum of a unimodal function of one variable $y(x)$ in a finite interval $x \in\langle a, b\rangle$. Further we suppose maximum of the function is

$$
y\left(x^{*}\right)=\max _{a \leq x \leq b} y(x) .
$$

The procedure was discovered and formally described in [17] as the way of determining an interval containing maximum of a unimodal function without any requirements on its continuity, derivatives etc. Thus the method is convenient for seeking maximum outcome of a real experiment that can be considered as a unimodal function of one variable.

The method is "minimax optimal" sequential method among the class of all sequential nonrandomized procedures with fixed number $\mathrm{N}$ of the argument values at which the function may be observed. Less formal description of the method can be found in [18]. FOS strategy is based on evaluation of the function (experiments) at $\mathrm{N}$ distinct points $x_{1}, x_{2}, \ldots x_{N}$ within the interval $\langle a, b\rangle$. Of course we do not know the value $x^{*}$. For unimodal function we can only claim that $x^{*}$ is somewhere in an interval $\left\langle x_{K-1}, x_{K+1}\right\rangle$ and for a given strategy $S_{N}$ we must consider the biggest possible interval. Strategy $S_{N}^{*}$ with minimal biggest possible interval is then "minimax optimal". Thus FOS method gives better results than other similar methods like dichotomic search or golden section search for the same number $\mathrm{N}$.

Next we describe FOS without mathematical details. Matlab Central File Exchange function fibonacciSearch can be consulted for implementation details of the minimum seeking method. FOS uses Fibonacci numbers $F_{n}$

$$
F_{n+2}=F_{n+1}+F_{n}, F_{0}=F_{1}, n=0,1,2, \ldots
$$

TABLE I

Table Showing Numerical Results of Maximum Seeking. Final UI IS $\langle 0.4585,0.5385\rangle$ WITH $\hat{x}=0.4985$.

\begin{tabular}{c|cccccc}
\hline $\mathrm{n}$ & $\mathrm{a}$ & $\mathrm{p}$ & $\mathrm{q}$ & $\mathrm{b}$ & $\mathrm{f}(\mathrm{p})$ & $\mathrm{f}(\mathrm{q})$ \\
\hline 6 & 0 & 0.3846 & 0.6154 & 1 & 0.490902 & 0.481671 \\
5 & 0 & 0.2308 & 0.3846 & 0.6154 & 0.437884 & 0.490902 \\
4 & 0.2308 & 0.3846 & 0.4615 & 0.6154 & 0.490902 & 0.499659 \\
3 & 0.3846 & 0.4615 & 0.5385 & 0.6154 & 0.499659 & 0.496582 \\
2 & 0.3846 & 0.4585 & 0.4615 & 0.5385 & 0.499536 & 0.499659 \\
& 0.4585 & & & 0.5385 & & \\
\hline
\end{tabular}

and Fibonacci sequence

$$
\left\{F_{n}\right\}_{n=0}^{\infty}=\{1,1,2,3,5,8,13,21,34,55, \ldots\} .
$$

Contrary to other sequential nonrandomized procedures we must set number of experiments $\mathrm{N}$ according to required precision or tolerance $t o l$ at the beginning of search. Let us denote interval containing $x^{*}$ as uncertainty interval (UI). Thus at the beginning of the search we have the first UI $\langle a, b\rangle$ with length $|b-a|$. FOS with N Fibonacci numbers decreases UI to final interval with length $\Delta$

$$
\Delta=\frac{|b-a|}{F_{N}} .
$$

From this follows that when we want to find optimum $x^{*}$ with given precision or tolerance $x^{*} \in\langle\hat{x}-t o l ; \hat{x}+t o l\rangle$ using minimum number of experiments, we must find smallest $\mathrm{N}$ satisfying

$$
F_{N}>\frac{|b-a|}{2 \cdot t o l} .
$$

Then we shall use Fibonacci numbers from sequence $\left\{F_{n}\right\}_{n=1}^{N}=\left\{F_{1}, F_{2}, \ldots, F_{N-1}, F_{N}\right\}$ to reduce UI gradually. The algorithm in Fig. 3 describes FOS method for maximum seeking.

In the Fig. 2 and Table I we demonstrate results of the algorithm on seeking the maximum of function $y=0.5-(x-$ $0.48)^{2}$ with $x^{*}=0.48$ in the interval $\langle 0,1\rangle$ with $t o l=0.04$ which yields $N=6$ and $\hat{x}=0.4985$.

\section{HEAT PUMP MODEL AND CONTROL LOOP}

Fibonacci search method was applied on a heat pump model, which was connected to a vehicle cabin. Both the heat pump and the vehicle cabin parameters does not correspond to any real vehicle parameters, but they were chosen to be approximately equivalent to possible real fully electric vehicle.

\section{A. Heat pump model}

The heat pump model was assembled in Dymola tool employing Modelica language and Air Conditioning library by Modelon. All control algorithms were designed in Matlab/Simulink as well as simulations were performed using this environment. Matlab/Simulink does not allow utilization of Modelica models and that is why the model was exported into Functional Mock-up Unit (FMU) and then loaded into Matlab using FMUtoolbox [19]. 


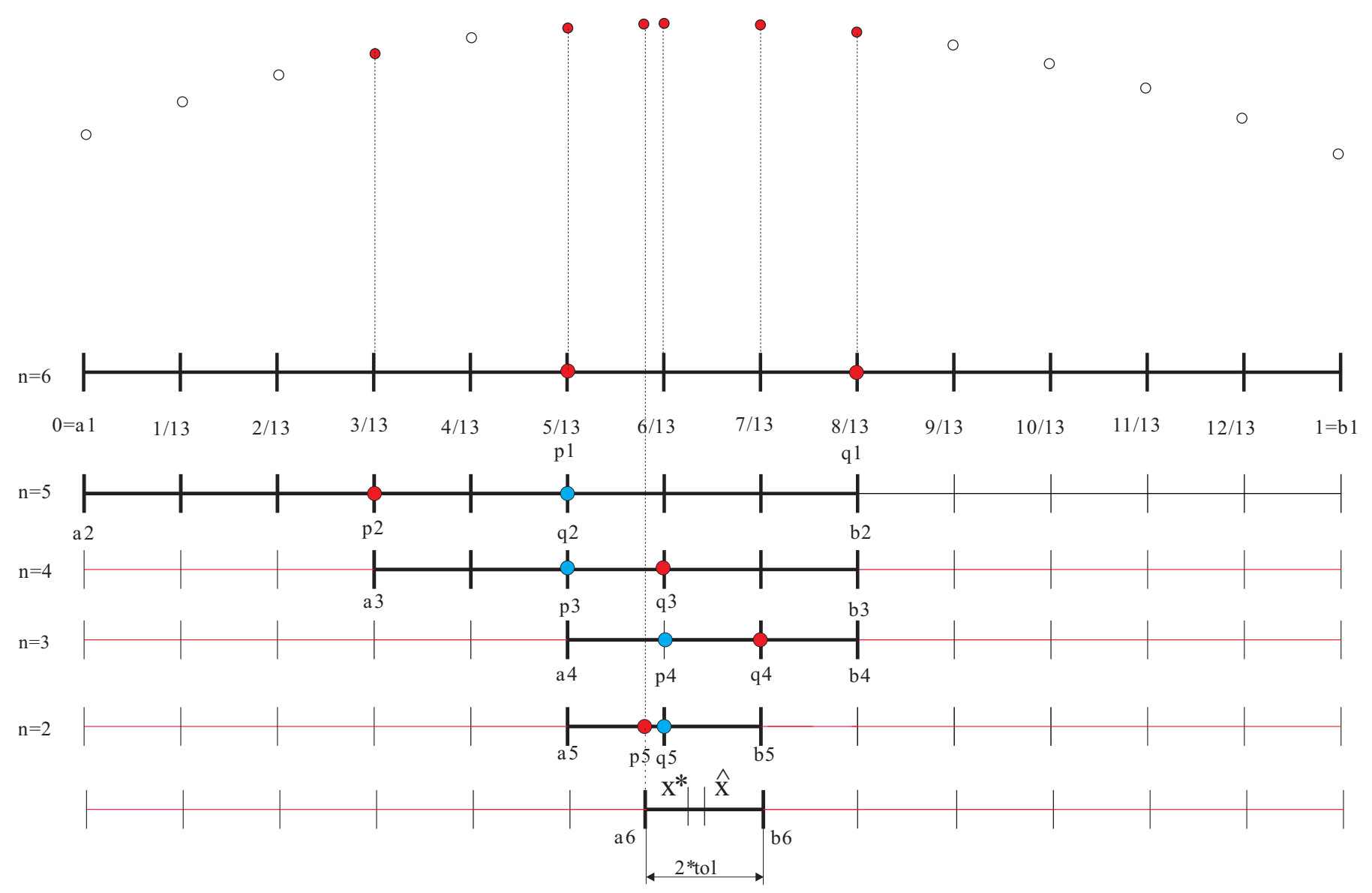

Fig. 2. Figure demonstrating function of FOS algorithm. Bold black intervals represent UIs. Red points represent experiments.

We selected the simplest possible system of R744 heat pump with high side pressure control (see Fig. 4). It consists of a compressor with variable displacement, an electronic expansion valve (EXV), an internal heat exchanger (IHX), an evaporator, a low pressure receiver and a gas cooler. In this system configuration it is possible to vary the high-side refrigerant charge and thus the high-side pressure using EXV flow factor change [1]. The superfluous refrigerant charge can be kept inside the low pressure receiver.

The heat pump model is connected to a vehicle cabin, as can be seen in Fig. 5. The cabin parameters were selected to represent a passenger vehicle. It is complemented by a fan and an air valve, which can be used to control ratio of fresh and recirculated air. Moreover we added a solar heat flow representing a heat gain from sun.

\section{B. Control loop}

The heat pump is actually a nonlinear coupled multipleinput and multiple-output (MIMO) system. However the effects of nonlinearity and coupling are not very strong, so we can consider it as a decoupled linear system. The control scheme is shown in Fig. 6 and it employs Modelica vehicle model, two PI controllers and Fibonacci algorithm. There are two setpoints, $\vartheta_{S P}$ denotes cabin temperature setpoint adjusted by user and $p_{S P}$ as high-side pressure setpoint whose value is determined by Fibonacci search method. $\vartheta$ stands for measured air temperature inside vehicle cabin, $p$ for measured high-side pressure and $C O P$ is coefficient of performance. PI controllers $P I_{\vartheta}$ and $P I_{p}$ take these variables and based on their differences compute values of control variables compressor displacement $\left(c_{d}\right)$ and EXV flow factor $\left(K_{v}\right)$. Modelica model could not be used for PI controllers tuning due to its very high complexity. Therefore transfer functions were obtained from simulations of this model and then were used for PI controllers tuning.

\section{Simulations}

The control loop with vehicle model, PI controllers and Fibonacci algorithm were connected using Matlab/Simulink as shown in Fig. 10. This control scheme was used for all simulation experiments in this paper, only parameters of blocks were changed. The subsystem "Temp and pressure control" contains PI controllers and related blocks. The component named "Fibonacci search method" is C S-function containing all code needed to find a COP maximum using mentioned method. It is possible to adjust an amount of fresh air supplied into vehicle cabin using the constant "fresh air". The start of Fibonacci algorithm can be influenced by setting parameters of pulse generator named "start" and also multiple starts are possible using this block. 
Fig. 3. FOS maximum seeking algorithm

Require: $a, b$, tol

1: $n=N \%$ Given $t o l$ find $N$

$\%$ Perform the first two experiments

$\%$ with arguments $p$ and $q$ i.e. $f(p) ; f(q)$

2: $p=b-\frac{F_{n-1}}{F_{n}}|b-a|$

3: $q=a+\frac{F_{n-1}^{n}}{F_{n}}|b-a|$

4: $f p=f(p)$

5: $f q=f(q)$

6: $n=n-1$

7: repeat

$\%$ Perform one experiment with argument $p$ or $q$

8: $\quad$ if $f p>f q$ then

9: $\quad b=q$

10: $\quad q=p$

11: $\quad p=b-\frac{F_{n-1}}{F_{n}}|b-a|$

12: $\quad f q=f p$

13: $\quad f p=f(p)$

14: $\quad$ else

15: $\quad a=p$

16: $\quad p=q$

17: $\quad q=a+\frac{F_{n-1}}{F_{n}}|b-a|$

$f p=f q$

$f q=f(q)$

end if

$n=n-1$

until $n>2$

$\%$ Perform last experiment with argument $p$ or $q$

23: if $f p>f q$ then

24: $\quad b=q$

25: $\quad q=p$

26: $\quad p=b-2 *$ tol

27: $\quad f q=f p$

28: $\quad f p=f(p)$

9: else

30: $\quad a=p$

31: $\quad p=q$

32: $\quad q=a+2 *$ tol

33: $\quad f p=f q$

4: $\quad f q=f(q)$

5: end if

\%Final step evaluating final interval of uncertainty

6: if $f p>f q$ then

37: $\quad b=q$

38: else

39: $\quad a=p$

40: end if

41: return $\hat{x}=(a-b) / 2$

All simulation experiments had the same ambient conditions representing a hot summer day. The ambient air temperature was $40{ }^{\circ} \mathrm{C}$ and at the start of the experiment the cabin air was at temperature of $58.5^{\circ} \mathrm{C}$ and cabin metal mass was $45^{\circ} \mathrm{C}$.

The first experiment (Fig. 7) consisted of vehicle cabin cool

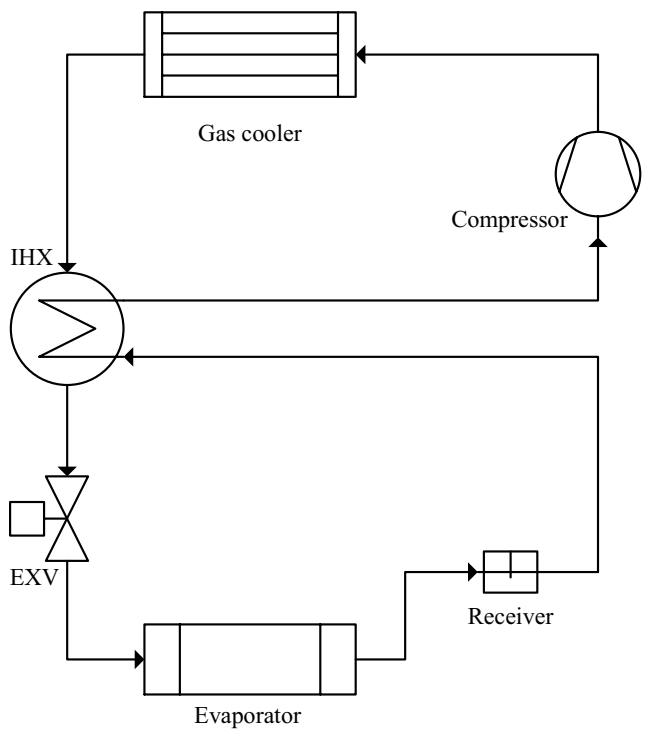

Fig. 4. R744 heat pump configuration.

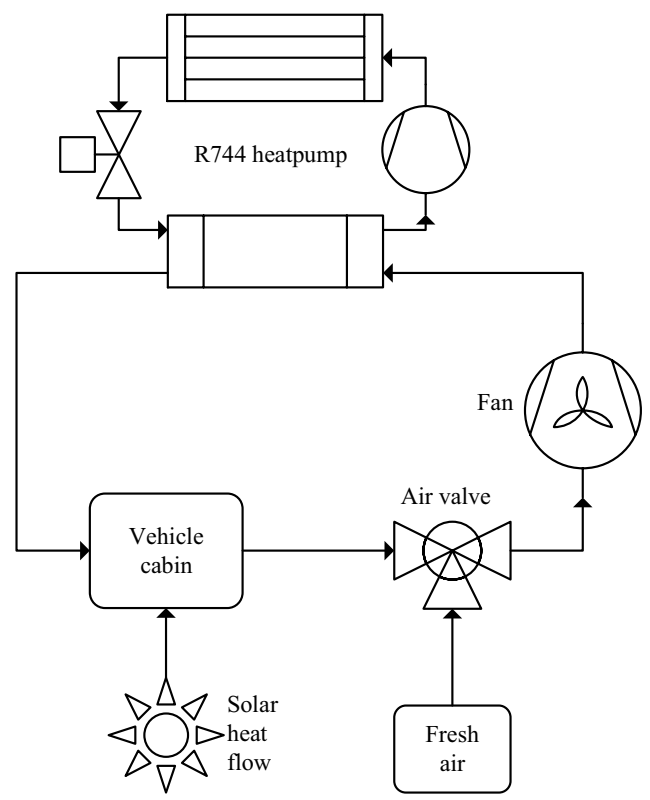

Fig. 5. R744 heat pump with vehicle cabin and HVAC equipment.

down to a reference temperature of $26^{\circ} \mathrm{C}$ and then searching the optimal high-side pressure using Fibonacci method. The temperature setpoint was constant during the simulation and after settling the cabin temperature was almost equal with maximum error of $0.15^{\circ} \mathrm{C}$ during the optimum searching. The air valve was completely closed, what means that all cabin air was recirculated and no fresh air was supplied into the vehicle cabin.

The second experiment was simulated under the same initial conditions as the first one, only the air valve was completely opened (all cabin air was exhausted outside and only fresh air 


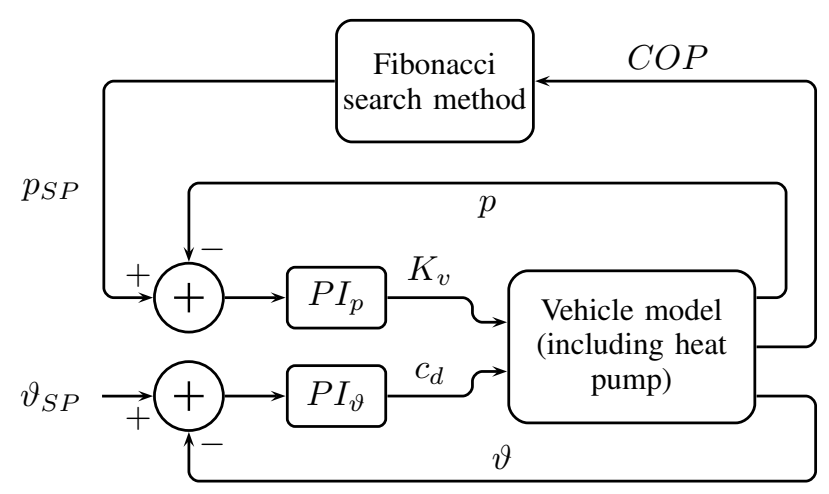

Fig. 6. R744 heat pump control loop.
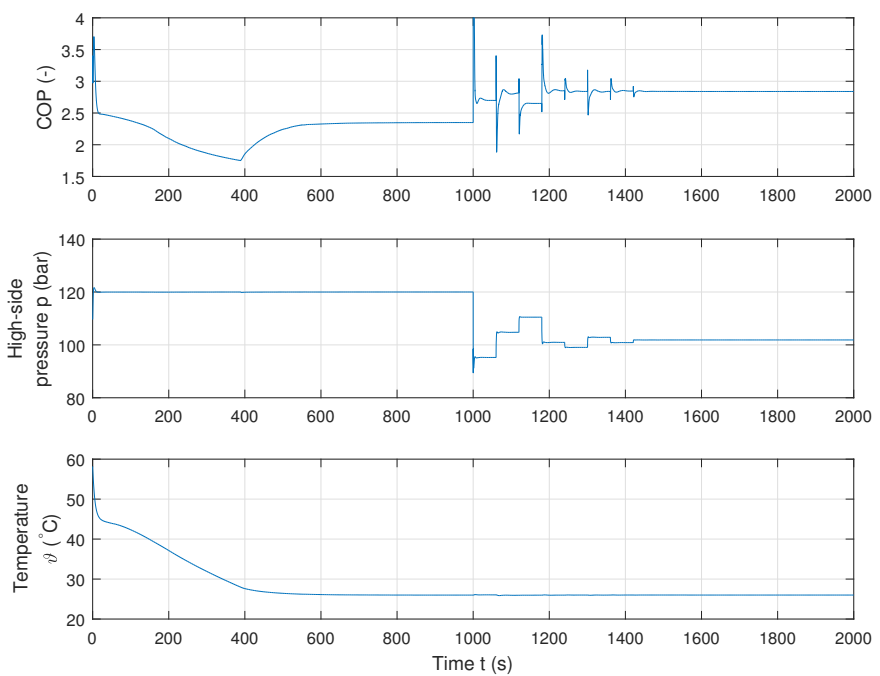

Fig. 7. Vehicle cabin cool down and COP maximum searching (recirculated air).
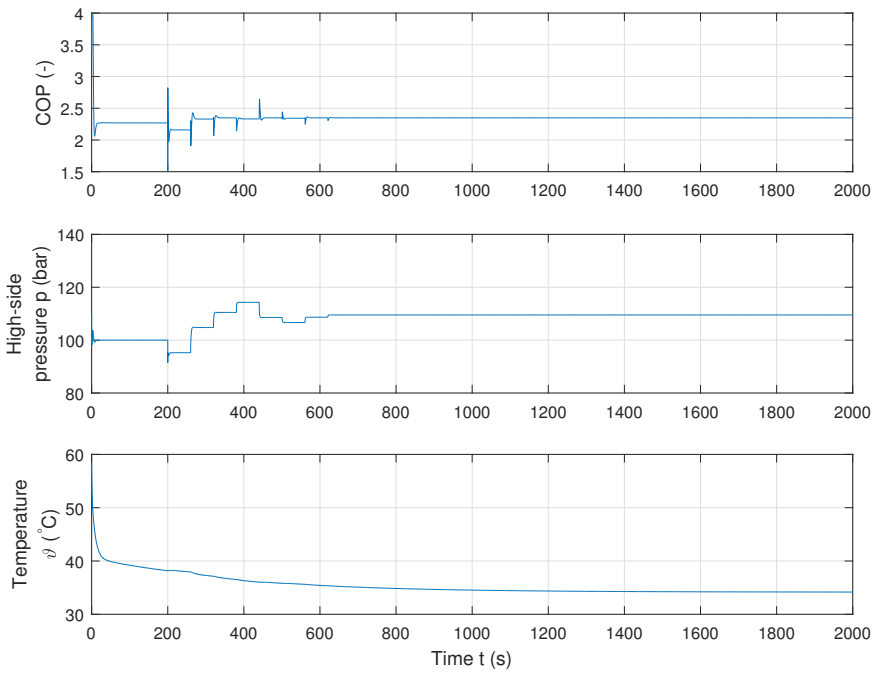

Fig. 8. Cooling vehicle cabin (with fresh air from outside).

was sucked into the cabin). The result is shown in Fig. 8.

The last simulation was almost the same as the second,
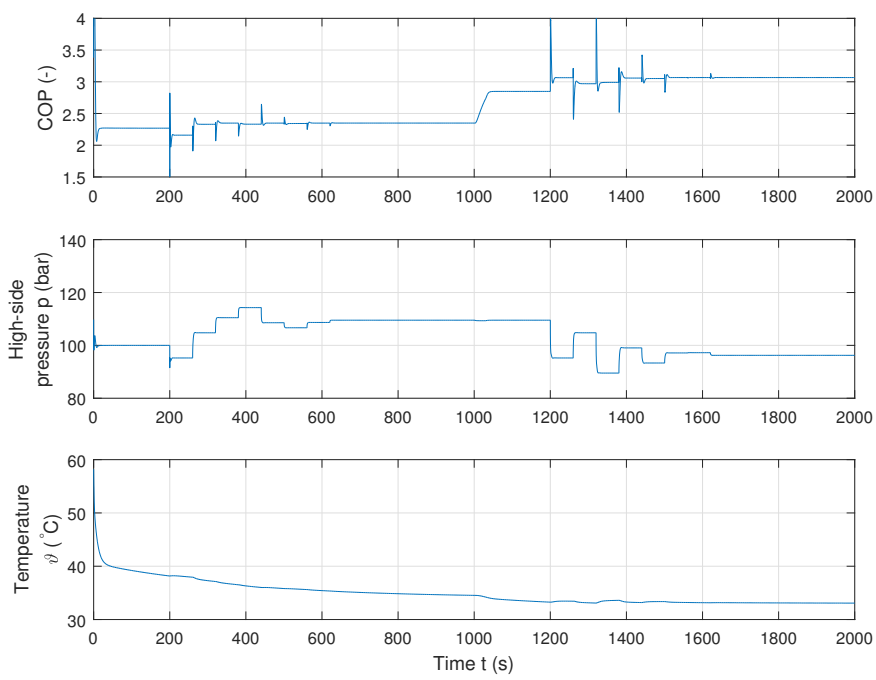

Fig. 9. Cooling vehicle cabin (with fresh air from outside) and ambient temperature change.

but at the time of $1000 \mathrm{~s}$ a change of ambient temperature occurred. The temperature fell from $40^{\circ} \mathrm{C}$ to $30^{\circ} \mathrm{C}$ during a $30 \mathrm{~s}$ ramp. After that change the optimal high-side pressure was considerably different, so a new run of Fibonacci search method was started at the time of $1200 \mathrm{~s}$. After approximately $200 \mathrm{~s}$ a new high-side pressure setpoint (96.2 bar) was found, what is quite far from the previous optimal pressure setpoint (109.5 bar), with a COP improvement of 0.22 .

\section{CONCLUSION}

In this paper we proposed a novel method of R744 heat pump high-side pressure determination using Fibonacci optimum seeking method. This method operates in real-time, what brings significant advantages over the offline methods (which use tables or some static equations). Firstly, the method is resistant against parameter changes and disturbances, which can often occur. Secondly, no pre-measured data or expressions, both describing relationship between heat pump cycle variables and optimal high side pressure, are necessary for the method operation (compared to offline methods, which usually need some). The main drawback of the method is the fact that it can not be used during fast transients.

The FOS method of optimal high-side pressure searching was verified using simulations in Matlab Simulink and employing heat pump model, which was constructed with the use of Modelica language.

We presented three examples of optimal high-side pressure searching. All of them demonstrated the method suitability for this purpose, the COP maximum was found during quite short time and with minimum changes of control input (EXV opening degree). This makes our method preferable against extremum seeking methods with continuous perturbation, where the lifetime of the EXV can be shortened due to frequent changes (valve hunting).

Future work will focus on method verification during heat pump real operation. It might require combining FOS method 


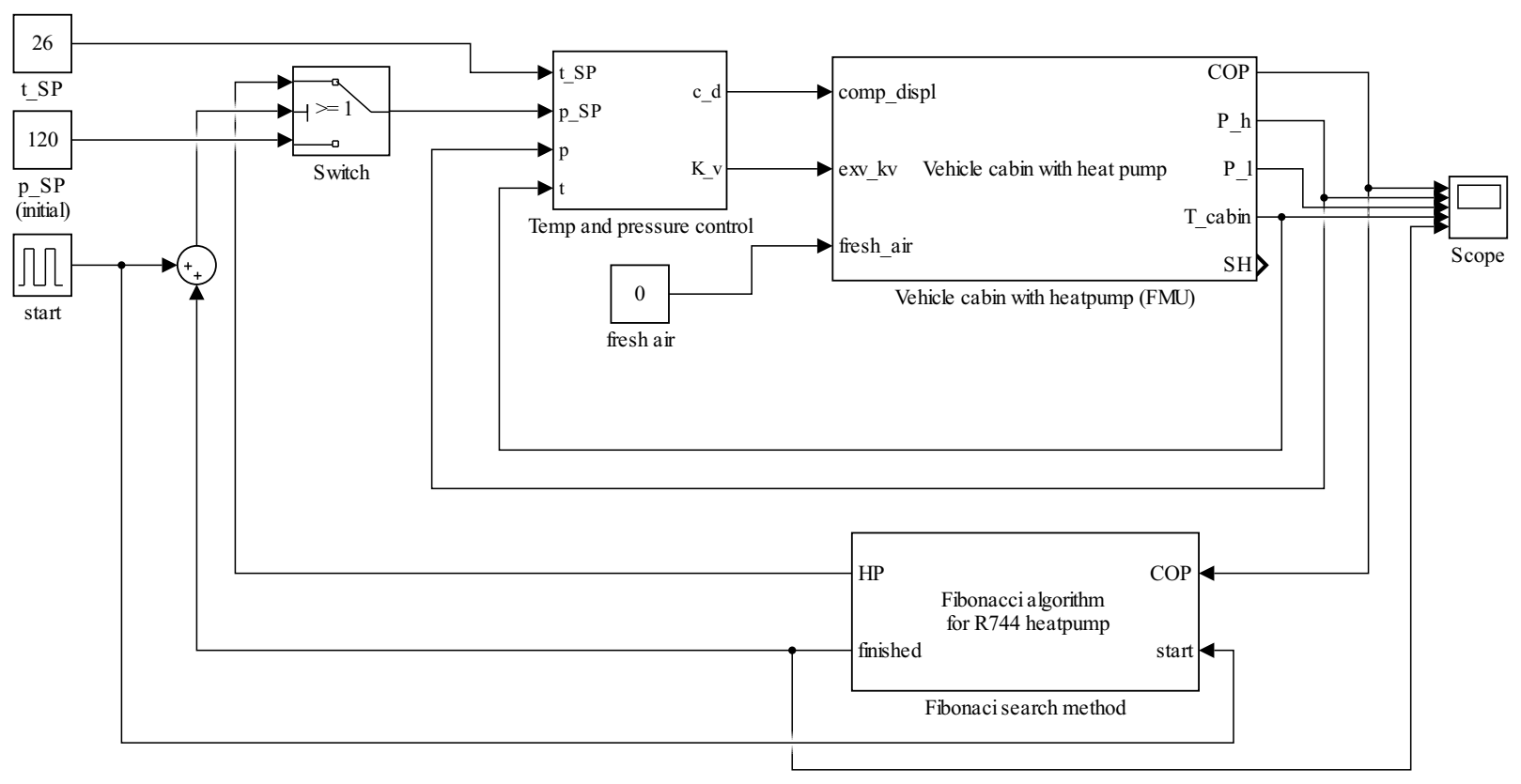

Fig. 10. Matlab control loop for vehicle cabin with heat pump and Fibonacci algorithm.

with some offline method to ensure the highest possible COP even during fast transients. Obviously there are several ways to improve the basic heat pump control, what will be subject of future research. Particularly the heat pump could be controlled as a nonlinear MIMO system, what can bring more precise control and thus some energy savings and longer lifetime of the actuators.

\section{ACKNOWLEDGMENT}

This research was carried out under the project H2020 653514 OSEM-EV - Optimised and Systematic Energy Management in Electric Vehicles. The research was supported by research infrastructure of CEITEC - Central European Institute of Technology.

The research results were verified in simulation using AVL CRUISE M simulation SW provided by AVL within University Partnership Program.

\section{REFERENCES}

[1] M. H. Kim, J. Pettersen, and C. W. Bullard, "Fundamental process and system design issues in $\mathrm{CO} 2$ vapor compression systems," Progress in Energy and Combustion Science, vol. 30, no. 2, pp. 119-174, 2004.

[2] J. M. Belman-Flores, V. Pérez-García, J. F. Ituna-Yudonago, J. L. Rodríguez-Muñoz, and J. d. J. Ramírez-Minguela, "General aspects of carbon dioxide as a refrigerant," Journal of Energy in Southern Africa, vol. 25, no. 2, pp. 96-106, 2014. [Online]. Available: http://www.scopus.com/inward/record.url?eid=2s2.0-84954217971\&partnerID=tZOtx3y1

[3] Y. Ma, Z. Liu, and H. Tian, "A review of transcritical carbon dioxide heat pump and refrigeration cycles," Energy, vol. 55, pp. 156-172, 2013.

[4] A. Sethi, E. Vera Becerra, and S. Yana Motta, "Low GWP R134a replacements for small refrigeration (plug-in) applications," International Journal of Refrigeration, vol. 66, pp. 64-72, 2016.

[5] P. Nekså, "CO2 heat pump systems," International Journal of Refrigeration, vol. 25, no. 4, pp. 421-427, 2002.

[6] C. Aprea and A. Maiorino, "Heat rejection pressure optimization for a carbon dioxide split system: An experimental study," Applied Energy, vol. 86, no. 11, pp. 2373-2380, 2009.
[7] G. Lorentzen and J. Pettersen, "A new, efficient and environmentally benign system for car air-conditioning," International Journal of Refrigeration, vol. 16, no. 1, pp. 4-12, jan 1993. [Online]. Available: http://www.sciencedirect.com/science/article/pii/014070079390014Y

[8] F. Kauf, "Determination of the optimum high pressure for transcritical CO2-refrigeration cycles," International Journal of Thermal Sciences, vol. 38, no. 4, pp. 325-330, apr 1999. [Online]. Available: http://linkinghub.elsevier.com/retrieve/pii/S1290072999800982

[9] S. Liao, T. Zhao, and A. Jakobsen, "A correlation of optimal heat rejection pressures in transcritical carbon dioxide cycles," Applied Thermal Engineering, vol. 20, no. 9, pp. 831-841, 2000.

[10] Y. Chen and J. Gu, "The optimum high pressure for $\mathrm{CO} 2$ transcritical refrigeration systems with internal heat exchangers," International Journal of Refrigeration, vol. 28, no. 8, pp. 1238-1249, 2005.

[11] J. Sarkar, S. Bhattacharyya, and M. Gopal, "Optimization of a transcritical $\mathrm{CO} 2$ heat pump cycle for simultaneous cooling and heating applications," International Journal of Refrigeration, vol. 27, no. 8, pp. 830-838, 2004.

[12] L. Cecchinato, M. Corradi, and S. Minetto, "A critical approach to the determination of optimal heat rejection pressure in transcritical systems," Applied Thermal Engineering, vol. 30, no. 13, pp. 1812-1823, 2010.

[13] L. Cecchinato, M. Corradi, G. Cosi, S. Minetto, and M. Rampazzo, "A real-time algorithm for the determination of R744 systems optimal high pressure," International Journal of Refrigeration, vol. 35, no. 4, pp. 817-826, 2012.

[14] B. Hu, Y. Li, F. Cao, and Z. Xing, "Extremum seeking control of COP optimization for air-source transcritical $\mathrm{CO} 2$ heat pump water heater system," Applied Energy, vol. 147, pp. 361-372, 2015.

[15] M. S. Kim, C. S. Shin, and M. S. Kim, "A study on the real time optimal control method for heat rejection pressure of a $\mathrm{CO} 2$ refrigeration system with an internal heat exchanger," International Journal of Refrigeration, vol. 48, pp. 87-99, 2014.

[16] M. Subasi, N. Yildirim, and B. Yildiz, "An improvement on Fibonacci search method in optimization theory," Applied Mathematics and Computation, vol. 147, no. 3, pp. 893-901, 2004.

[17] J. Kiefer, "Sequential Minimax Search for a Maximum," Proc. American Mathematical Society 4, pp. 502-506, 1953.

[18] D. J. Wilde, Optimum seeking methods. Prentice Hall, 1964.

[19] J. Glos, "FMUtoolbox for Matlab/ Simulink," in 22nd Conference STUDENT EEICT 2016. Brno: Vysoké učení technické v Brně, Fakulta elektrotechniky a komunikačních technologií, 2016, pp. 426-430. 